\title{
Reaction of the reproductive system of hens to the chronic stressor
}

\author{
M. Sakhatsky, Yu. Osadcha*, V. Kuchmistov \\ National University of Life and Environmental Sciences of Ukraine, 15, Heroiv Oborony Str, Kyiv, 03041, \\ Ukraine
}

Corresponding author E-mail: seledat@ukr.net

Received: 01.07.2020. Accepted: 01.08.2020

\begin{abstract}
The urgency of detecting chronic stressors by the egg laying capacity of hens is connected with the lack of objective data on the amount of material losses during their operation. Due to it and the attempt to obtain as many food eggs as possible from $1 \mathrm{~m}^{2}$ of available technological areas, some of their powerful producers resort to keeping the laying hens in the cages of multitiered batteries and even at higher densities, ie not at the densities recommended by the developer of the cross, but at higher ones established by the domestic standards. Therefore, the aim of the experiment was to determine the response of the reproductive system of hens to the intensity of chronic stressors formed by keeping them in cages of 12-tier batteries at a slightly higher density. To do it, on the conditions of a modern complex of the alimentary egg production 3 groups of laying hens of industrial herd of the cross Hy-Line W-36 were formed, each was kept in a separate poultry house-analogue (area 2,463.3 $\mathrm{m}^{2}$ ) with 12-tier cages batteries "Salmet", consisting of 30912 cages with the area of $0.392 \mathrm{~m}^{2}$. Hens of the 1 st (control) group were kept at a density of 23 hens/m in accordance with domestic standards, and the 2 nd and 3rd groups - at overcrowding, ie at 26 and 28 hens $/ \mathrm{m}^{2}$, respectively. The effect of chronic stress on hens was determined by standard zootechnic and morphological methods of measuring their egg production, preservation, live weight and weight of eggs, strength and thickness of the shell, intensity of yolk color, etc. It was found that in accordance with the domestic requirements the normative density of keeping $\left(23 \mathrm{hens} / \mathrm{m}^{2}\right)$ of the hens of the cross Hy-Line W- 36 does not provide their inherent productivity, which should be at least 262.2 eggs per initial laying hen within 62 weeks of life (and at the density of keeping in the range of $13-20$ hens $\left./ \mathrm{m}^{2}\right)$. In particular, in hens of group 1 it was $(231.4$ eggs/hen), here it was $11.7 \%$ lower. Preservation of hens of group $1(91.3 \%)$ also did not reach the normative level $(96.4 \%)$. The increase in the intensity of chronic stressors, namely the increase in the density of hens of groups 2 and 3 to $26-28$ hens $/ \mathrm{m}^{2}$, led to a corresponding reaction of their body, in particular, to a decrease in egg productivity (up to $220.8-227.2 \mathrm{pcs} / \mathrm{hen}$.) and preservation (up to $88.4-91.1 \%$ ). This increase in the density of laying hens in the cages of 12 -tier batteries to $26-28$ hens $/ \mathrm{m}^{2}$ (by $4-27 \%$ relative to domestic standards) provides for obtaining of $1.6-5.2$ thousand more eggs from $1 \mathrm{~m}^{2}$ of poultry area, but under conditions of reduction of the level of the European coefficient of efficiency of their production. Thus, it was found that overcrowding of hens of the industrial flock of egg cross Hy-Line W-36 is a chronic stressor, which causes a decrease not only in egg production due to ovulatory cycles, but also their viability and efficiency of egg production in general.
\end{abstract}

Keywords: Laying hens; Egg-laying; Live weight; Viability; Density; Stressor

\section{Introduction}

Laying hens of modern egg crosses under optimal living conditions are able to lay up to 365 eggs per year (Guidelines for the maintenance of the final hybrid Hy-Line W-36, 2019), which is possible with daily ovulation of a new egg. Their wild ancestors (Gallus bankiva) usually lay only 3-9 eggs during this time (Bird Life International, 2016). During 3-5 millennia of breeding domesticated hens, mankind has created many populations and breeds, including specialized egg crosses, the laying hens of which are able to lay eggs daily under certain conditions. They usually ovulate once a day, 30 minutes after laying an egg (Shtele, 2014). Theoretically, it can occur up to 4 times a day, but under the conditions of laying eggs without the shell, for the formation of which the laying hen's body spends up to 19 hours (Naumenko et al., 2009).

Many factors affect the rhythmicity of the ovulatory cycle, and hence the laying of hens. Until recently, the nutritional factor was considered to be the most influential, associated with their water and food supply, its balance of essential nutrients (Fisinin \& Kavtarashvili, 2015). Nowadays, a stress factor is also considered the one, to the influence of which laying hens can be exposed at any time during a long productive period. Usually a stressful situation, which arises, for example, due to limited access to water or food, soon leads to aggressive behavior of individuals that suppress other laying hens. It is believed that stress factors can be infections, invasions, overcrowding, too high or low air temperature, poor sanitation and other irritants (Fisinin \& Kavtarashvili, 2015; Grasteau et al., 2015). New relations between laying hens in stressful situations arising from keeping them in sections of the poultry house in large groups (1-2 thousand hens) are more significant than in small ones (3-30 hens) - when keeping them in cages (Kicheeva et al., 2019). These new relationships are mostly caused by the struggle for dominance in the herd or in a certain area and can turn from one behavioral form to another depending on the situational conditions of existence (Favati et al., 2014). With a uniform supply of food in the area of maintenance, the territorial form of the relations between the individuals of the herd prevails, and with 
uneven or deficit - dominant. However, aggression and the establishment of new hierarchical relations are characteristic to both of these forms (Marino, 2017).

The body's response to the action of a stimulus (stressor) depends on the intensity and duration of its impact to the formation of characteristic features, the specifics of this action, the biological characteristics of the object of influence and other factors (Siegel, 1995; Zhuchaev et al., 2019; Lin et al., 2006). In any case, stressful situations require the body to spend extra energy to adapt to new living conditions, changes in instinctive behavior, which leads to a decrease in egg production by $19.3-28.8 \%$ due to violations of the ovulatory cycle, their viability and egg quality (Mashaly et al., 2004; Kim et al., 2015; Fisinin \& Kavtarashvili, 2015). A decrease in their egg production due to stress factors is also associated by other researchers with a wide range of behavioral, physiological and immunological interdependent changes in the body of hens with (El-Lethey et al., 2010; Khan et al., 2011; Surai \& Fotina, 2013). Certain behavioral actions of hens in stressful situations are accompanied by a $34.7 \%$ decrease in feed consumption (Mashaly et al., 2004; Abidin \& Khatoon, 2013), disruption of the endocrine system (Attia et al., 2009), and acid-base balance (Borges et al., 2004), decrease of the antioxidant status, inhibition of the functions of individual organs and physiological mechanisms (Fisinin \& Kavtarashvili, 2015). In particular, elevated levels of corticosterone, noradrenaline, and adrenaline lead to disregulation of physiological processes related to steroidogenesis and, consequently, to follicle growth, their development, and ovulation (Yakubu et al., 2006; Oguntunji \& Alabi, 2010). There is also a weakening of the synthesis and release of vitellogenin, which is required for the formation of egg yolk (Joachim et al., 2010). Adrenaline "in vitro" has been shown to cause follicular atresia (Moudgal \& Razdan, 1985). Its high concentration in the body inhibits ovulation and, consequently, the egg laying, high concentration of corticosterone leads to the destruction of ovarian (Edens \& Siegel, 1976).

Stress is divided into 2 types, acute and chronic. They are similar in physiological mechanisms, but differ in the duration of the stimulus and the intensity of the reaction to it. The acute type is characterized by an extremely high level of response, especially for certain unexpected actions, in particular, for catching laying hens during vaccination or transportation from one farm to another, for changing the method of keeping (from floor to cage or vice versa), for sudden switching off lights in the poultry house, etc. Signs of chronic stress occur due to the action of a less powerful stimulus over a long period of time, ie gradually, rather than suddenly. The level of reaction to the periodic action of one or more stimuli can be both insignificant and increase to a high level due to deteriorating conditions of laying hens, the spread of a disease of non-infectious nature in the herd, improper work of personnel or technological equipment (Zhuchaev et al., 2019). Increase of the density of hens by only 1 hens $/ \mathrm{m}^{2}$ of the poultry floor area without the increase of its ventilation regime can lead to stress due to reduced feeding and watering fronts, increase of the temperature by $20 \%$ and double air pollution by microflora (Kavtarashvili \& Kolokol'nikova, 2010).

The effects of chronic stress vary depending on the species of animals, their breed characteristics or stage of the life cycle, housing conditions, the specifics of the stimulus and other factors (Fisinin \& Kavtarashvili, 2015; Compton et al., 1981; Koelebeck \& Cain, 1984; Abilov \& Strebkova, 2018), and its diagnosis is somewhat complicated due to lack of relevant criteria. In laying hens, the effect of acute stress has an immediate negative effect on their egg production. However, the effectiveness of detecting chronic stress in the laying level of hens, especially at the beginning of the stimulus, has not been studied yet. This also applies to stimuli formed by increasing the density of laying hens in cages. The urgency of detecting chronic stressors precisely because of the laying of hens is connected with the lack of objective data on the amount of material losses during their action. Due to it and the attempt to obtain as many food eggs as possible from $1 \mathrm{~m}^{2}$ of available technological areas, some of their powerful producers resort to keeping the laying hens in the cages of multi-tiered batteries and even at higher densities established by the domestic standards, ie not at recommended by the developer of the cross.

The aim of the study was to determine the response of the reproductive system of hens to the intensity of chronic stressors, formed by keeping them in cages of 12-tier batteries at a slightly higher density.

\section{Methods}

In the conditions of a modern complex on production of food eggs (Kyiv region) 3 groups of laying hens of an industrial herd of cross Hy-Line W36 (Table 1) were formed, each of which was kept in a separate poultry house-analogue in the area $\left(2463,3 \mathrm{~m}^{2}\right)$, equipped with 12-tier cage batteries "Salmet" (Germany), consisting of 30,912 cages with an area of $0.392 \mathrm{~m}^{2}(0.70 \times 0.56 \mathrm{~m})$.

The experiment lasted 43 weeks, namely from the beginning of laying (at the age of 19 weeks) to 62 week-old age of the hens. They were provided with drinking water, complete feed of the same composition and kept in accordance with the requirements (VNTP, 2005). The difference between the groups was only the density of laying hens, the level of which depended on their number in the cages, and this led to different provision of the feeding front.

Table 1. The scheme of the experiment.

\section{Characteristics}

Laying hen

- in 1 cage

- in a group

Stocking density, hens/ $\mathrm{m}^{2}$

Supply of area, $\mathrm{cm}^{2} /$ hen

Feeding area, $\mathrm{cm}^{2} / \mathrm{hen}$

\section{1 (control)}

9

278208

23

435.6

7.78

\section{Group of laying hens}

2

10

309120

26

392.0

7.00
3

11

340032

28

356.4 
As for the density of hens in cages, in accordance with domestic standards (VNTP-APK-0.4.05) it should be in the range of 22-25 hens $/ \mathrm{m}^{2}$ (supply of the area of $400-450 \mathrm{~cm}^{2} / \mathrm{hen}$ ), and according to the requirements of the cross developer's guide (Hy-Line W-36 Final Hybrid Content Guide, 2019) - in the range of $13-20 \mathrm{hens} / \mathrm{m} 2\left(490-750 \mathrm{~cm}^{2} / \mathrm{hen}\right)$ and with the supply of the feeding front not less than $7.0 \mathrm{~cm}^{2} /$ hen. (Therefore, as shown in Table 1, the density of hens in the control group corresponded to the domestic standards, and in the experimental - did not.

During the experiment, the number of laid eggs and laying intensity, the number of rejected hens (due to death and culling) were determined daily in groups and the preservation of livestock was determined. Once a week, the weight of eggs and live weight of laying hens were measured from certain labeled cages which were at least $100(n \geq 100)$. The European coefficient of efficiency of egg production (Kavtarashvili, 2013) was determined by the formula:

$$
\text { Eer }=(1.4 \times M)-(0.35 \times C) \text {, }
$$

where: 1.4 and 0.35 - constant values; $\mathrm{M}$ - egg mass, $\mathrm{kg} / \mathrm{hen} ; \mathrm{C}$ - feed conversion.

The results are presented like mean and standard error. The data were analyzed using Statistica 12.0 software (StatSoft Inc., 2014, www.statsoft.com). Differences between the values of the control and experimental groups were determined using ANOVA, where the differences were considered reliable at $p<0.05$ (taking into account Bonferroni correction).

\section{Results}

According to the experimental data (Table 2), there were 30912 hens more in the (by $11.1 \%$ ) due to increase in the keeping density, and in the 3 group - by 61824 hens (by 22.2\%) than in the control group (1 group). However, the overcompacted keeping of laying hens of all 3 groups in relation to the parameters recommended by the developer of the cross, as well as 2 and 3 groups - even in relation to more severe domestic standards, has led to a decrease in their preservation and other negative consequences.

Table 2. Laying of hens depending on the intensity of influence of chronic stressors.

\section{Feature}

Total number of laying hens in the experiment, hens

- At the beginning

- in the end

- Rejected (death and culling)

Viability of laying hens, \%

Received total eggs, pcs., including:

- Per $1 \mathrm{~m}^{2}$ of poultry area;

- For the initial laying hen

Euro efficiency of egg production, c. u.

Live weight of laying hens, $\mathrm{kg}$

- At 52 weeks age

- At 62 weeks age

Weight of eggs, $g$

- At 52 weeks age

- At 62 weeks age

$\mathbf{1}$ (control)
278208
254004
24202
$91.3 \pm 0.05$
64377331
26135
$231.4 \pm 0.23$
$19.7 \pm 0.07$
$1.52 \pm 0.00$
$1.53 \pm 0.00$
$63.7 \pm 0.04$
$65.7 \pm 0.02$

$\begin{array}{ll}\mathbf{2} \text { Group of laying hens } \\ 309120 & \mathbf{3} \\ 281608 & 340032 \\ 27512 & 300588 \\ 91.1 \pm 0.05 * * & 39444 \\ 68253696 & 88.4 \pm 0.10^{* *} \\ 27708 & 77255270 \\ 220.8 \pm 0.09 * * & 31363 \\ 19.1 \pm 0.07 * * & 19.2 \pm 0.47 * * \\ & \\ 1.52 \pm 0.00 & 1.45 \pm 0.07^{* *} \\ 1.54 \pm 0.01 & 1.50 \pm 0.01^{*} \\ & \\ 64.2 \pm 0.01 & 65,0 \pm 0.03^{* *} \\ 66.6 \pm 0.01^{* *} & 65,9 \pm 0.04 * *\end{array}$

Bonferroni correction).

Therefore, according to the guidelines of the developer of the cross (Hy-Line W-36 Final Hybrid Content Guide, 2019), the preservation of laying hens in the herd at the 62 week of life should be at least $96.4 \%$. However, in group 1 it was only $91.3 \%$, and in groups 2 and 3 it was even smaller $-88.4-91.1 \%$, which is due to the intensity of influence of the chronic stimulus on the laying hen. Thus, if the hens of group 1 were kept not according to the density of the severe domestic standards ( $22-25 \mathrm{hens} / \mathrm{m}^{2}$, or $400-450 \mathrm{~cm}^{2} /$ hen), but according to standards recommended by the developer of the cross $\left(13-20 \mathrm{hens} / \mathrm{m}^{2}\right.$, or $490-750 \mathrm{~cm}^{2} /$ hen), then their preservation would correspond to the predicted level. But, in that case, the number of hens in group 1 would be slightly smaller, 216,384 hens at the beginning of the experiment and 208,594 hens. - In the end. Their loss would be no more than 7790 hens (instead of 18825 hens with the preservation of $91.3 \%)$.

This difference (11,035 hens) in number of the lost laying hens is a pay-off for more severe conditions of their keeping. Thus, keeping hens for 43 weeks at a density above the recommended level leads to a decrease in their preservation by $5.1 \%$, here to the consequences that usually occur during prolonged exposure of birds under the influence of chronic stress stimuli.

On the background of this control group, a further increase in the density of laying hens in groups 2 and 3, here the intensification of the studied stimulus, led to the corresponding negative consequences. In these groups there were 3310 and 15242 more laying hens (by $13.7-63.0 \%$ ) than in the control group.

The laying hens of the cross Hy-Line W-36 should lay at least 262.2 eggs within 62 weeks of life, but at the recommended keeping density (13-20 hens $\left./ \mathrm{m}^{2}\right)$ (Hy-Line W-36 Final Hybrid Content Guide, 2019). As it can be seen from the experimental data (Table 2), keeping them in group 1 under a little harsher conditions $\left(23 \mathrm{hens} / \mathrm{m}^{2}\right)$ caused a decrease in egg production by 30.8 eggs $(13.3 \%)$, namely to 231.4 egg per hen. Intensification of the influence of the stimulus by increasing the density of hens to 26 hens $/ \mathrm{m}^{2}(2 \mathrm{nd}$ group) led to a decrease in their egg production by another 10.6 eggs (up to 220.8 egg per hen). Even higher intensification (up to 28 hens $/ \mathrm{m}^{2}$ ) did not lead to the expected reaction (3rd group). Laying of the hens in this group was 227.2 egg per hen, here it was 6.4 eggs more than in 2 nd groups. The reason for the illogical reaction of the hens of group 3 to further increase of the effect of stressors was found after clarification of the actual density of their keeping, taking into account the current preservation. Thus, due to its low level $(88.4 \%)$, the initial number of hens decreased from 11 to 9.7 hen/cage by the end of the experiment, and the density of their keeping - from 28 to 24.7 hens $/ \mathrm{m}^{2}$. In fact, it decreased to 24.7 hens $/ \mathrm{m}^{2}$ much earlier, during the first 10 weeks of the experiment. During the 43 weeks of the experiment, it was during the first 10 of them that the vast majority of the 39,444 dead and culled laying 
hens were rejected. Therefore, for a long time the density of the rest of the hens of the 3rd group was even lower than the density of the 2 nd group ( 24.7 and 26.0 hens $/ \mathrm{m}^{2}$, respectively), which affected their egg production.

It should be noted once again that at the beginning of the experiment in the same area of poultry houses in groups 2 and 3 there were by $30,912(11.1 \%)$ and $61,824(22.2 \%)$ laying hens more than in group 1 due to increased density in cages up to $26-28$ hens/m ${ }^{2}$. Due to it, in groups 2 and 3 more eggs were obtained in total and per $1 \mathrm{~m}^{2}$ of the poultry area, despite a significant $(p<0.001)$ reduction in egg production. In particular, in the 2 group an additional 1573 eggs were obtained from $1 \mathrm{~m}^{2}$ of poultry area, in the 3 group - 5228 pieces, but at a slightly lower level than in the control level of the European coefficient of efficiency of their production (Table 2). In addition, in comparison with the 1 control group, 3310 and 15242 laying hens more were lost in these two experimental groups. Their pre-slaughter live weight would be 5130 and $23625 \mathrm{~kg}$, respectively. Thus, increase of the density in cages of laying hens of the cross Hy-Line W-36 to 26-28 hens/ $\mathrm{m}^{2}$ provides a slightly larger number of food eggs from $1 \mathrm{~m}^{2}$ of technological areas, but with a decrease in the efficiency of their production and additional losses of laying hens.

By comparing the curves of the actual (Figure 1) and the standard intensity of laying of hens the current level of egg-forming process in the herd is considered and if abnormality is identified measures are taken to eliminate them. The egg-laying intensity of the hens of the cross Hy-Line W-36 at 20 weeks of their life should be at least 50\%, at 22-23-90\%, at 24-25-95-96\%. This peak level should last 10-12 weeks and only then gradually decrease to $86 \%$ by 62 weeks of life. According to the curves above (Figure 1) egg production of hens of all 3 groups began at the age of 19 weeks, i.e., with a delay of 1 weeks. Its intensity of hens of 1 and 3 groups grew faster than of the 2 group.

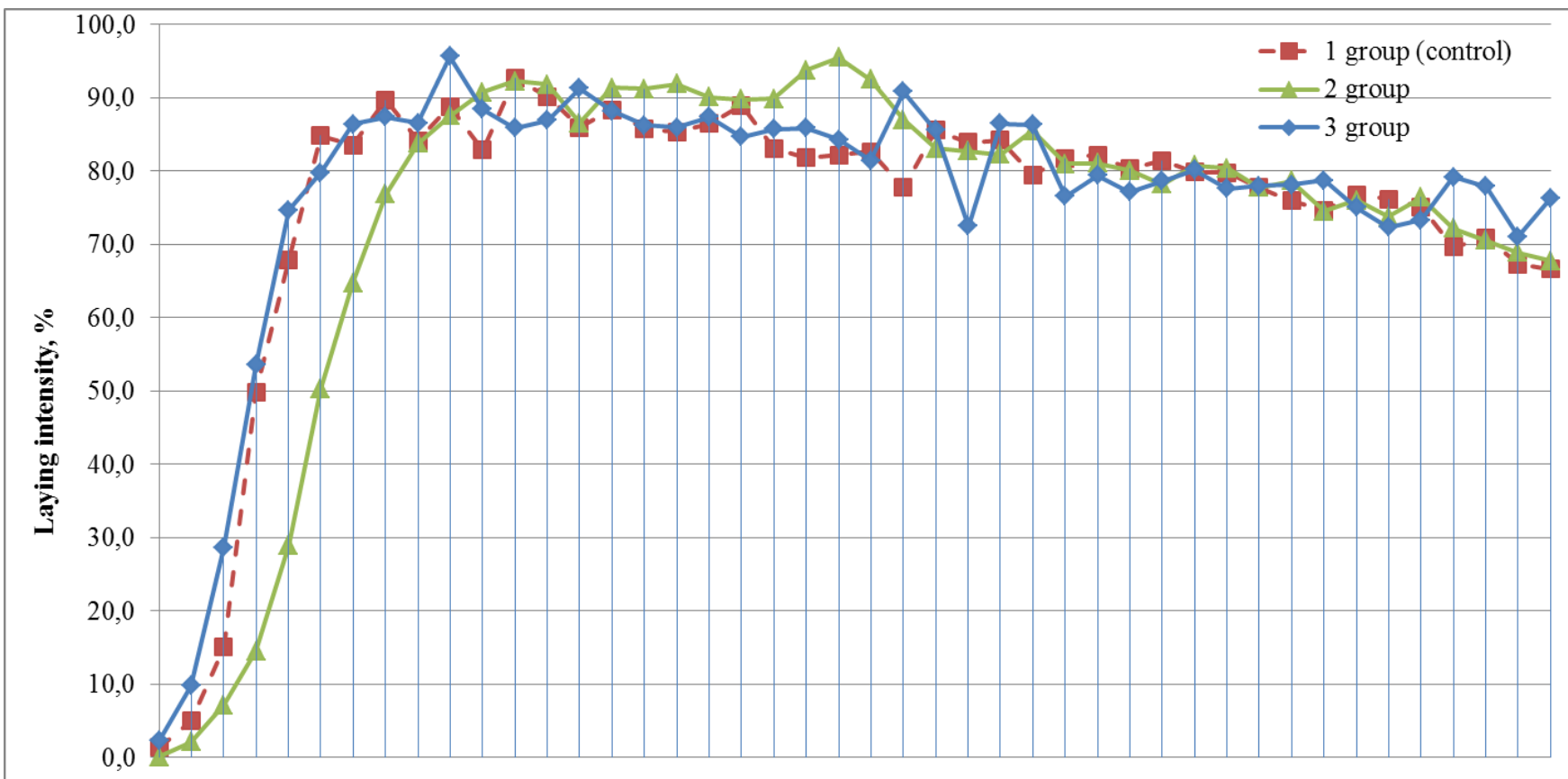

1920212223242526272829303132333435363738394041424344454647484950515253545556575859606162

Weeks of age

Figure 1. The intensity curve of laying of the hens.

They reached $50 \%$ of the level of its intensity at 22 weeks of age, and of the 2 group - at 24 weeks. Hens of group 1 reached the level of $90 \%$ at 24 weeks of age, the peak level (92\%) - at 29-30 weeks (with some fluctuations), and at 62 weeks - decreased to $67 \%$. Hens of group 2 reached the level of $90 \%$ at 29 weeks of age, it reached the regulatory peak (96\%), only at 40 week of age. Laying hens of group 3 reached the regulatory peak level a little earlier, at 28 weeks of age, but it was short-time. At 62 weeks of age, they outnumbered their counterparts in other groups. Therefore, the configurations of the intensity curves of laying of the hens of all groups do not coincide with the regulatory curve from the beginning to the end of the experiment. This indicates a relatively uniform, here without cumulative effect on this feature of the studied chronic stressor throughout the 43-week observation period. However, this effect sometimes briefly resembles situations that occur at the unexpected action of an acute stimulus.

Live weight of hens of the cross Hy-Line W-36 at 52 and 62 weeks of age should be $1.54-1.58 \mathrm{~kg}$, and egg weight - 62.9 and $63.4 \mathrm{~g}$, respectively (Hy-Line W-36 Final Hybrid Content Guide, 2019). The weight of eggs met these requirements in all groups of hens, and live weight - only the 1st and 2nd. In laying hens of group 3, it was slightly smaller, which indicates a possible additional impact on them of the chronic stress of an alimentary nature due to less provision of the feeding front during the first 10 weeks of the experiment. The effect of laying hen density on the strength and thickness of the shell, the intensity of yolk color and other characteristics of the constituent eggs, including Haugh units, was not detected.

\section{Discussion}

The increase in the volume of food eggs obtained by poultry complexes is provided nowadays mainly by the modernization of existing productions. To do it, manufacturers usually replace 1-3-tier cage batteries of obsolete structures with new, 6-12-tier ones. With the replacement of 3-tier batteries by 12-tier, the number of seats in the poultry house with an area of $2463.3 \mathrm{~m}^{2}$ increases from 69.6 to 278.2 thousand of laying hens, i.e., 4 times. Accordingly, the volume of eggs obtained per year as a whole and per $1 \mathrm{~m}^{2}$ of its area (from 9.6 to 38.4 thousand pieces) increases 4 times. It is especially important for businesses that lack vacant land to build new poultry houses. But even modernized enterprises seek to further increase of egg production due to the high consumer demand for them in domestic or foreign markets. To do it, they resort to increasing the number of laying hens. Of course, if the poultry house is filled with 
another batch of pullets on the eve of the expected increase in demand for eggs, they are placed in each cage by one or more hens above the normative number. This leads to their compaction, the level of which depends on the number of additionally planted laying hens. It is known (Mashaly et al., 2004; Kim et al., 2015; Fisinin et al., 2015; Zhuchaev et al., 2019) that keeping birds in high density and other inappropriate conditions lead to numerous negative consequences. As the results of our experiment have proven, it fully concerns hens of the studied egg cross. Their over compaction has led to the stress characteristic of its chronic form. The effect of the stressor on the body of hens, namely on its reproductive capacity, was felt throughout the 43-week period of the experiment (i.e., until the age of 62 weeks). The negative consequences of this effect were adequate to its intensity, i.e., the level of overcrowding of laying hens. They responded to the stimulus by reducing egg production and viability. In particular, with the increase of the density of keeping from 13-20 hens $/ \mathrm{m}^{2}$, which is the standard for the hens of the cross Hy-Line W-36, to 23 hens/ $\mathrm{m}^{2}$, they did not reach their inherent egg-laying capacity - 262.2 egg per hen. Within 62 weeks of life. It amounted to only 231.4 egg per hen, here it was lower by $11.7 \%$. The actual preservation of laying hens (91.3\%) was also lower than the standard $(96.4 \%)$. With the increase of the density of keeping to $26-28$ hens $/ \mathrm{m}^{2}$, i.e. with an even greater increase in the intensity of the stimulus, the laying of hens decreased to $220.8-$ 227.2 egg per hen (by 13.3-15.8\%), and preservation - up to 88.4-91.1\%. However, this increase in the density of hens still made it possible to obtain more eggs from $1 \mathrm{~m}^{2}$ of poultry area by 1.6-5.2 thousand pieces, but with a decrease in the efficiency of their production and additional losses of laying hens.

We did not find the effect of the studied chronic stressor on the weight, parameters of other quantitative and qualitative characteristics of eggs. Their deviations from the standard level, which occur from time to time on farms, are probably the result of other, more intense chronic or acute stressors. Obviously, this can happen when the laying hens consume poor-quality feed, which lacks certain nutrients, or contains compounds that interfere with their assimilation.

This experiment did not determine the maximum level of intensity of the stimulus, the excess of which would lead to the development of the chronic stage of stress into acute. Such a task, important not only from a theoretical point of view, was not set at all. It is advisable to carry out its solution on a small flock of laying hens in a vivarium. Bringing the large number of laying hens of industrial poultry to acute stress would lead to significant material losses. Its signs are a certain behavioral response of hens, cessation (or significant reduction) of egg production with increasing mortality in the herd due to ovulation disorders, reduction of live weight and egg weight (Miftahutdinov, 2014; Fisinin et al., 2017), their quality and consumer characteristics (Royo et al., 2008; Babacanoğlu et al., 2013; Zabudskii, 2017). With regard to chronic stress caused by a slightly higher density of hens, for the first time in this experiment 3 signs that indicate its occurrence have been revealed: 1) certain deviations in the dynamics of egg intensity from the standard curve; 2 ) reduction of egg production by $11.7-15.8 \% ; 3$ ) reduction of viability by $5.1-8.0 \%$.

\section{Conclusions}

1. Overcrowding of laying hens of egg cross Hy-Line W-36 is a chronic stressor, which negatively affects not only their egg production, here cyclic ovulation, but also viability. Increasing the density of their content in the cages of 12 -tier batteries from $13-20$ hens/m ${ }^{2}$, here from the normative for this cross to the level provided by domestic standards $\left(22-25\right.$ hens $\left./ \mathrm{m}^{2}\right)$, leads to a decrease in egg production for 62 weeks of life from 262,2 egg per hen up to 231.4 egg per hen (by $11.7 \%$ ) and preservation from $96.4 \%$ to $91.3 \%$ (by $5.1 \%$ ).

2. Increasing the intensity of chronic stressors by increasing the retention density to $26-28$ hens $/ \mathrm{m}^{2}$, leads to a corresponding reaction of the body of hens, namely to a further decrease in their egg productivity (up to 220.8-227.2 egg per hen) and preservation (up to 88.4-91.1\%).

3. Increasing the density of laying hens in the cages of 12 -tier batteries to $26-28$ hens $/ \mathrm{m}^{2}$ (by $4-27 \%$ relative to domestic standards) ensures the production of eggs from $1 \mathrm{~m}^{2}$ of poultry house area by 1.6-5.2 thousand (20\%) more, but for reducing the level of European efficiency of their production.

4. No direct influence of the studied stressor on the parameters of traits dependent on nutritional factors, in particular on the live weight of laying hens, egg weight, strength and thickness of their shells, the intensity of yolk color and some others.

\section{References}

Abidin, Z., \& Khatoon, A. (2013) Heat stress in poultry and the beneficial effects of ascorbic acid (vitamin C) supplementation during periods of heat stress. World's Poultry Science Journal. 69, 135-151.

Abilov, B.T., \& Strebkova, K.A. (2018). Ispol'zovanie razlichnyh priemov povyshenija sohrannosti kur (obzor) [The use of various methods to improve the safety of chickens (review)]. News of science and agribusiness. 2(11), 218-222. (in Russian).

Attia, Y.A., Hassan, R.A., \& Qota, M.A. (2009). Recovery from adverse effects of heat stress on slow-growing chicks in the tropics. 1: Effect of ascorbic acid and different levels of betaine. Tropical Animal Health and Production. 41, 807-818.

Babacanoğlu, E., Yalcin, S. \& Uysal, S. (2013). Evaluation of a stress model induced by dietary corticosterone supplementation in broiler breeders: Effects on egg yolk corticosterone concentration and biochemical blood parameters. British poultry science. 54, 67785.

Bird Life International (2016). Gallus gallus. The IUCN Red List of Threatened Species 2016: e.T22679199A92806965.

Borges, S.A., Fischer Da Silva, A.V., Majorka, A., Hooge, D.M., \& Cummings, K.R. (2004). Physiological responses of broiler chicken to heat stress and electrolyte balance (sodium plus potassium minus chloride, milliequivalent per kilogram). Poultry Science. 83, 15511558.

Compton, M.M., van Krey, H.P., Ruszler, P.L., Gwazdauskas, F.C. (1981). The effects of claw removal and cage design on the production performance, gonadal steroids, and stress response in caged laying hens. Poultry Science. 60(9), $2127-2135$.

Edens, F.W., \& Siegel, H.S. (1976). Modification of corticosterone and glucose responses by sympatholytic agents in young chickens during acute heat exposure. Poultry Science. 55, 1704-1712.

El-Lethey, H., Aerni, V., Jungi, T.W., \& Wechsler, B. (2000). Stress and feather pecking in laying hens in relation to housing conditions. British Poultry Science. 41, 22-28.

Favati, A., Leimar, O., Radesater, T., \& Lovlie, H. (2014). Social status and personality: stability in social state can promote consistency of behavioural responses. Proc. R. Soc. B 28: 20132531, 1-8.

Fisinin, V.I., \& Kavtarashvili, A.Sh. (2015). Teplovoj stress u pticy. Soobshhenie I. Opasnost', fiziologicheskie izmenenie v organizme, priznaki i projavlenija [Heat stress in birds. Message I. Danger, physiological changes in the body, signs and manifestations]. Agricultural biology. 50(2), 162-171. (in Russian). 
Fisinin, V.I., \& Kavtarashvili, A.Sh. (2015). Teplovoj stress u pticy. Soobshhenie II. Metody i sposoby profilaktiki i smjagchenija (obzor) [Heat stress in birds. Message II. Methods and methods of prevention and mitigation (review)]. Agricultural biology. 50(4), 431-443. (in Russian).

Fisinin V. I., Miftahutdinov A.V., Amineva Je.M. (2017). Invazivnaja i neinvazivnaja diagnostika adaptacionnyh reakcij mjasnoj pticy pri primenenii stress-protektornogo antioksidanta [Invasive and non-invasive diagnostics adaptive reactions of poultry when using a stressprotective antioxidant]. Sel'skohozjajstvennaja biologija [Agricultural biology]. 52 (6), 1244-1250.

Grasteau, S., Moreri, U., Narcy, A., Rousseau, X., Rodenburg, B., Tixier-Boichard, M., \& Zerjal, T. (2015). Robustness to chronic heat stress in laying hens: A meta-analysis. Poultry science. 94. doi.10.3382/ps/pev028.

Hy-Line W-36 Final Hybrid Content Guide (2019).

Joachim, J.A., Joseph, O.A., \& Sunday, A.O. (2010). Effects of heat stress on some blood parameters and egg production of Shika Brown layer chickens transported by road. Biological Research. 43, 183-189.

Kavtarashvili, A.Sh., \& Kolokol'nikova, T.N. (2010). Fiziologija i produktivnost' pticy pri stresse [Physiology and productivity of birds under stress]. Agricultural biology. 4, 24-37.

Kavtarashvili, A.Sh. (2013.) Opredelenie jeffektivnosti proizvodstva pticevodcheskoj produkcii jekspress-metodami [Determining the efficiency of poultry production by express methods]. Economics. 2(123), 6-9.

Khan, R., Naz, S., Nikousefat, Z., Tufarelli, V., Javdani, M., Rana, N., \& Laudadio, V. (2011). Effect of vitamin E in heat-stressed poultry. World's Poultry Science Journal. 67(3), 469-478.

Kicheeva, T.G., Gluhova, Je.R., \& Panuev, M.S. (2019). K voprosu jetologii sel'skohozjajstvennoj pticy pri tehnologicheskom stresse [To the question of the ethology of poultry under technological stress]. Agrarian Bulletin of the Upper Volga. 2(27), 76-78. (in Russian). Kim, Yeon-Hwa, Kim, Jimin, Yoon, Hyung-Sook, \& Choi, Yang-Ho. (2015). Effects of Dietary Corticosterone on Yolk Colors and Eggshell Quality in Laying Hens. Asian-Australasian Journal of Animal Sciences. 28(6), 840-846.

Koelebeck, K.W., \& Cain, J.R. (1984). Performance, behavior, plasma corticosterone and economic returns of laying hens in several management alternatives. Poultry Science. 63(11), 2123-2131.

Lin, H., Jiao, H.C., Buyse, J., \& Decuypere, E. (2006). Strategies for preventing heat stress in poultry. World's Poultry Science Journal. $62,71-86$.

Marino, L. (2017). Thinking chickens: a review of cognition, emotion, and behavior in the domestic chicken. Animal Cognition. 20, 127147.

Mashaly, M.M., Hendricks, G.L., Kalama, M.A., Gehad, A.E., Abbas, A.O., \& Patterson, P.H. (2004). Effect of heat stress on production parameters and immune responses of commercial laying hens. Poultry Science. 83, 889-894.

Miftahutdinov, A. V. (2014). Jeksperimental'nye podhody k diagnostike stressov v pticevodstve (obzor) [Experimental approaches to the diagnosis of stress in poultry farming (review)]. Sel'skohozjajstvennaja biologija [Agricultural biology]. 2, 20-30.

Moudgal, R.P., \& Razdan, M.N. (1985). In vitro studies on ovulatory mechanisms in the hen. Journal of Veterinary Medicine. 32, 179186.

Naumenko, V.V., Djachins'kij, A.S., Demchenko, V.Ju., \& Derev'janko, I.D. (2009). Fiziologija sil's'kogospodars'kih tvarin [Farm animal physiology]. Centr uchbovoï literaturi, Kïiv (in Ukrainian).

Oguntunji, A.O., \& Alabi, O.M. (2010). Influence of high environmental temperature on egg production and shell quality: a review. World's Poultry Science Journal. 66, 739-749.

Siegel, H.S. (1995). Stress, strains and resistance. British Poultry Science. 36, 3-22.

Shtele, A. L. (2014). Povyshenie yajczenoskosti u vysokoproduktivnykh kur i problema ego rannego prognozirovaniya[Increased egg production in highly productive chickens and the problem of its early prediction]. Sel skokhozyajstvennaya biologiya [Agricultural biology]. 6, 26-35.

Surai, P.F., \& Fotina, T.I. (2013). Physiological mechanisms of stress development in poultry industry. Animal Breeding Today. 6, 5460.

Royo, F., Mayo, S., \& Carlsson H. \& Hau, J. (2008). Egg Corticosterone: A Noninvasive Measure of Stress in Egg-laying Birds. Journal of avian medicine and surgery. 22. 310-4.

VNTP-APK-04.05. (2005). Vidomchi normi tehnologichnogo proektuvannja. Pidpriemstva ptahivnictva: zatv. nakazom Min-vom agrar. politiki Ukraïni vid 15.09.2005 r. № 473. [Departmental standards of technological design. Poultry enterprises: approved by the order of the Ministry of Agrarian Policy of Ukraine No. 473 of 15.09.2005.] Kiiiv. (in Ukrainian).

Yakubu, A., Salako, A.E., \& Ige, O. (2007). Effect of genotype and housing systems on the laying performance of chickens in different season in the semi-humid tropics. International Journal of Poultry Science. 6(6), 434-439. doi:10.3923/ijps.2007.434.439.

Reproductive Function In Hybrid Poultry. IV. An Impact

Zabudskii Yu.I. (2017). Reproductive function in hybrid poultry. IV. An impact of maternal hormones accumulated in eggs (review). Agricultural biology. 52 (4), 686-689.

Zhuchaev, K.V., Sulimova, L.I ., \& Kochneva, M.L. (2019). Reakcija kur-nesushek jaichnogo krossa na hronicheskij i ubojnyj stress [The reaction of laying hens of egg cross to chronic and lethal stress]. Scientific notes of Kazan State Academy of Veterinary Medicine named after N.E. Bauman. 2 (238), 76-81. (in Russian).

\section{Citation:}

Sakhatsky, M., Osadcha, Yu., Kuchmistov, V. (2020). Reaction of the reproductive system of hens to the chronic stressor. Ukrainian Journal of Ecology, $10(4), 6-11$. 